\title{
Toxicity of exogenous fatty acid peroxides towards spermatozoa
}

\author{
R. Jones and T. Mann \\ A.R.C. Unit of Reproductive Physiology and Biochemistry, \\ University of Cambridge, U.K.*
}

\begin{abstract}
Summary. The toxicity of unsaturated fatty acids towards spermatozoa was shown to be directly related to their degree of peroxidation. The toxicity was manifested by an immediate arrest of motility and irreversible loss of respiratory and fructolytic activity. Repeated washing of spermatozoa, or the addition of fructose, lactate, or ATP, failed to restore these functions. The structural damage incurred as a result of the fatty acid peroxides was particularly evident in the acrosomal region. Partial protection from the adverse effects of these peroxides was provided by prior treatment of spermatozoa with dialysed egg yolk or milk, but tocopherol, albumin and mercaptoethanol were ineffective. It is suggested that lipid peroxides or their degradation products, whether introduced exogenously or derived from the peroxidation of endogenous phospholipids in semen, constitute a potential hazard to the functional integrity of spermatozoa.
\end{abstract}

\section{Introduction}

Ever since it was established that lipid peroxides had mutagenic effects on cells (Wyss, Stone \& Clark, 1947; Dickey, Cleland \& Lotz, 1949; Ross, 1950; Loveless, 1951), there have been numerous reports on the cytotoxicity of these compounds. Fatty acid peroxides exert lethal effects when administered parenterally to mice, rabbits and chickens (Horgan, Philpot, Porter \& Roodyn, 1957; Findlay, Draper \& Bergan, 1970; Nishida, Tsuchiyama, Inoue \& Kummerow, 1960), and to cause intense pain when injected subcutaneously into human subjects (Ferreira, 1972). At a cellular level, lipid peroxides produce lesions in the mucosal lining of the lung and small intestine (Cortesi \& Privett, 1972; Olcott \& Dolev, 1963) and induce aggregation of erythrocytes and blood platelets (Tsen \& Collier, 1960; Mickel \& Horbar, 1974). Other work has indicated that the mechanism of action of these peroxides may be mediated through their destructive influence on proteins and enzymes. Bernheim, Wilbur \& Kenaston (1952) noticed that fatty acid peroxides inhibit the activity of certain oxidative enzymes, and later Roubal \& Tappel (1966) reported precipitation and loss of amino acids from purified proteins which had been exposed to the action of peroxidized arachidonic acid. Dubouloz \& Fondarai (1953) found that ethyl oleate peroxide oxidized SH groups of proteins, and subsequent studies (Wills, 1961, 1971; Lewis \& Wills, 1962) have demonstrated that SH-containing enzymes are in general more readily inhibited by lipid peroxides than other enzymes. Furthermore, sulphydryl compounds such as reduced glutathione confer some protection.

The available evidence, therefore, supports the view that exogenous fatty acid peroxides are highly cytotoxic, and that their effects are cumulative and irreversible. As a follow-up to our observations that the endogenous phospholipids of spermatozoa are susceptible to peroxidation and that this process leads to disruption of the plasma membrane and release of intracellular constituents (Jones \& Mann, 1973, 1976, 1977), we provide evidence in the present study that exogenously added fatty acid peroxides and their breakdown products exert a direct toxic effect on spermatozoa.

\section{Materials and Methods}

The methods for collecting semen, washing spermatozoa, assessing motility and the procedures for measuring oxygen uptake, fructolysis and enzyme activities have been described previously (Jones \& Mann, 1977). Pure fatty acids, egg-yolk lecithin and the so-called brain fractions III (mostly phos-

* Postal address: Animal Research Station, 307 Huntingdon Road, Cambridge CB3 0JQ, U.K. 
phatidyl serine) and V (mostly phosphatidyl ethanolamine) were purchased from Sigma Chemical Co. (London). Fatty acids were peroxidized by exposure to u.v. light from an Hanovia Lamp (240/250 $\mathrm{nm})$ at room temperature $\left(22^{\circ} \mathrm{C}\right)$. The peroxide values of the fatty acids were measured iodometrically by the procedure of Swoboda \& Lea (1958) and the results are expressed as nmol benzoyl peroxide/mg fatty acid. Emulsions of fatty acids and phospholipids were prepared in Krebs-Ringer solution, pH 7.0, by vigorous mixing on a rotamixer for 3-4 min. Egg yolk (diluted 1 to 4 with Ringer solution and centrifuged at $2000 \mathrm{~g}$ for $20 \mathrm{~min}$ ) was dialysed for $24 \mathrm{~h}$ against $0.9 \%$ (w/v) $\mathrm{NaCl}$ buffered with $5 \mathrm{~mm}-\mathrm{Na}$ phosphate, $\mathrm{pH} 7 \cdot 4$. Bull seminal plasma was dialysed against the Krebs-Ringer solution.

\section{Results}

\section{Effects of non-peroxidized and peroxidized fatty acids on spermatozoa}

When a suspension of washed ram spermatozoa $\left(0.4 \times 10^{9} / \mathrm{ml}\right)$ with vigorous motility was mixed with an equal volume of an emulsion of heavily peroxidized arachidonic acid (peroxide value $>1000$ $\mathrm{nmol} / \mathrm{mg}$ ), spermatozoa became immotile instantly. By contrast, an emulsion of arachidonic acid which had not been peroxidized or showed only a very low peroxide value $(<10 \mathrm{nmol} / \mathrm{mg})$ had no adverse effect on sperm motility. This was the first indication that fatty acid peroxides as such had a direct toxic action on spermatozoa. We therefore examined the effects exerted on the motility of fresh ram spermatozoa by saturated or unsaturated fatty acids, used either fresh or after exposure to u.v. light for $24 \mathrm{~h}$ (Table 1). Saturated fatty acids did not give a peroxide reaction either before or after exposure to u.v. light, and failed to immobilize spermatozoa; unsaturated fatty acids, even when freshly obtained and supposedly free from peroxides, gave a positive peroxide test and inhibited the motility of spermatozoa. The extent of this inhibition depended more on the level of peroxide in the suspension than on the concentration of the fatty acid itself. For example, a concentration of 5-6 mg fresh arachidonic acid (peroxide value $15.7 \mathrm{nmol} / \mathrm{mg}$ ) $/ \mathrm{ml}$ was required to immobilize spermatozoa completely, but as little as $1 \mathrm{mg}$ peroxidized arachidonic acid (peroxide value $82.0 \mathrm{nmol} / \mathrm{mg}$ ) $/ \mathrm{ml}$ sufficed to produce an almost instant effect. The same behaviour was shown by linoleic acid (18:2), linolenic acid (18:3) and docosahexanoic acid (22:6).

Table 1. Effect of peroxidized fatty acids on the motility of washed ram spermatozoa in a $3-\mathrm{ml}$ suspension $\left(0.56 \times 10^{9}\right.$ cells $\left./ \mathrm{ml}\right)$ after incubation for $5 \mathrm{~min}$ at $25^{\circ} \mathrm{C}$

\begin{tabular}{ccc}
\hline & $\begin{array}{c}\text { Final conc. of } \\
\text { peroxide } \\
\text { (nmol/mg fatty } \\
\text { acid)/ml }\end{array}$ & Motility index \\
\hline $16: 0$ & $0 \cdot 0$ & 3 \\
$18: 0$ & $0 \cdot 0$ & 3 \\
$18: 2$ & $50 \cdot 0$ & 0 \\
$20: 4$ & $82 \cdot 0$ & 0 \\
$22: 6$ & 36.0 & 0 \\
\hline
\end{tabular}

Spermatozoa from man, bull, boar, rabbit, rat, and stallion were also tested and all were immobilized by fatty acid peroxides, the level of peroxide just sufficient to render the spermatozoa immotile being comparable to the values recorded in Table 1 for the ram.

To provide evidence that the fatty acid peroxides are taken up and adsorbed onto the surface of spermatozoa, the following experiment was carried out. To $5 \mathrm{ml}$ of a suspension of washed ram spermatozoa in Ringer solution was added $5 \mathrm{ml}$ of an emulsion of peroxidized arachidonic acid ( $4 \mathrm{mg} / \mathrm{ml}$; peroxide value $92.0 \mathrm{nmol} / \mathrm{mg}$ ). One drop was removed to check that the spermatozoa had been completely immobilized, and the remaining suspension was centrifuged at $2500 \mathrm{~g}$ for $15 \mathrm{~min}$ to obtain the 'sperm' supernatant. A 'control' supernatant was prepared by centrifuging a mixture of $5 \mathrm{ml}$ Ringer solution and $5 \mathrm{ml}$ fatty acid emulsion. The 'sperm' supernatant was no longer toxic when 
Table 2. Concentration of protein $(\mathrm{mg} / \mathrm{ml})$ and activity of certain intracellular enzymes (units/l) in centrifuged supernatants $(5000 \mathrm{~g}$ for $20 \mathrm{~min}$ ) obtained from 5-ml suspensions of ram spermatozoa $\left(0.75 \times 10^{9} / \mathrm{ml}\right)$ incubated at room temperature for $1 \mathrm{~h}$

\begin{tabular}{lccc}
\hline & \multicolumn{3}{c}{ Supernatants from spermatozoa that were: } \\
\cline { 2 - 4 } & $\begin{array}{c}\text { Incubated } \\
\text { without } \\
\text { additions }\end{array}$ & $\begin{array}{c}\text { Incubated with } \\
8 \mathrm{mg} \text { peroxidized } \\
\text { docosahexanoic } \\
\text { acid }\end{array}$ & Cold shocked \\
\hline Protein & $0 \cdot 16$ & 1.48 & $1 \cdot 70$ \\
LDH & 95.4 & 811.0 & 954.5 \\
GOT & 11.0 & 108.2 & 69.9 \\
Hyaluronidase & 13.3 & 117.3 & 125.9 \\
Acid phosphatase & 10.8 & 54.1 & 54.1 \\
$\beta-N$-acetylglucos- & & & 98.2 \\
aminidase & 49.9 & 95.8 & \\
\hline
\end{tabular}

added to fresh spermatozoa, but the 'control' supernatant immediately abolished the motility of freshly added spermatozoa. Furthermore, when the pellet obtained by centrifuging the fatty-acidimmobilized spermatozoa was resuspended in fresh Ringer solution and sonicated, the resulting homogenate reduced the motility index of fresh motile spermatozoa from 4 to 1 .

Additional evidence that the fatty acid peroxides are taken up by the sperm cell was provided by microscopic examination of a sperm suspension to which had been added peroxidized arachidonic acid. At $\times 400$ magnification numerous tiny droplets were observed adhering to the surface of these spermatozoa, giving them a rather 'mottled' appearance. When such spermatozoa were examined under the transmission electron microscope, their plasma membranes were seen to be extensively damaged, particularly in the region of the acrosome. Biochemical evidence of damage to the cell membrane was provided by the release of intracellular enzymes into the surrounding medium (Table 2).

\section{Effects of fatty acid peroxides on the metabolic activity of spermatozoa}

The influence of fatty acid peroxides on the oxygen uptake and fructolysis of spermatozoa is illustrated in Text-fig. 1. In the presence of a toxic amount of arachidonic acid $\left(1.5 \mathrm{mg} / 10^{9}\right.$ cells;

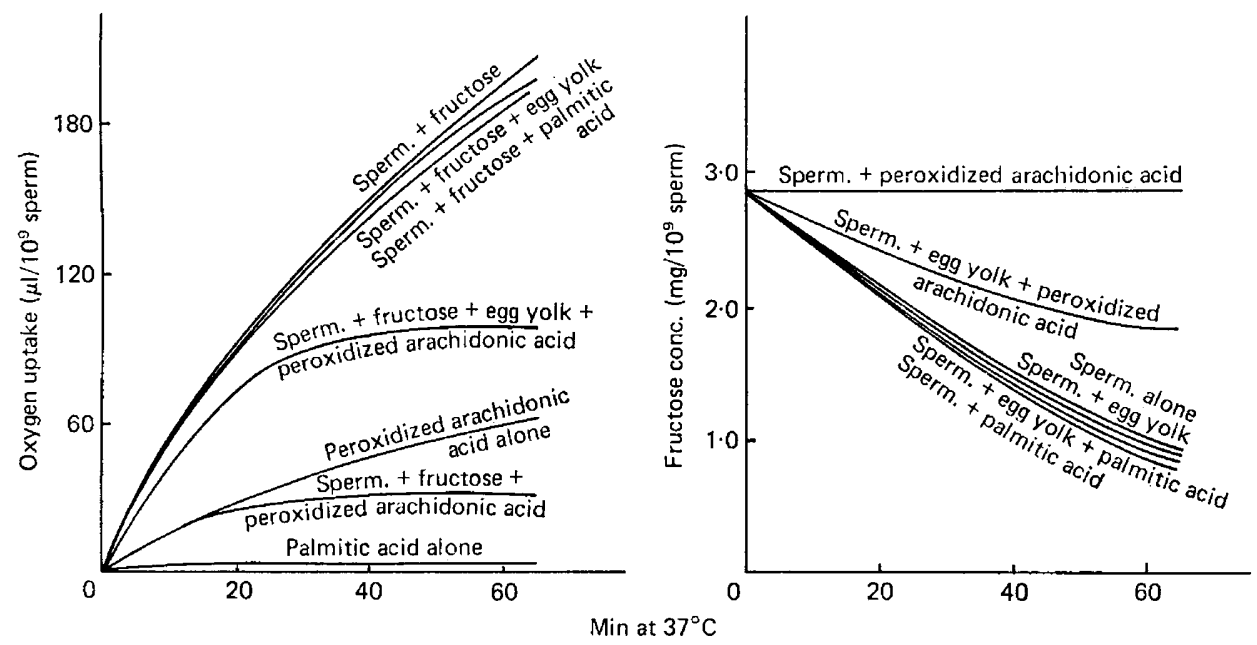

Text-fig. 1. Inhibitory effect of peroxidized arachidonic acid on the oxygen uptake and fructolysis of ram spermatozoa at $37^{\circ} \mathrm{C}$ and the protective role of dialysed egg yolk. Manometric readings of $\mathrm{O}_{2}$ uptake were taken at 10 -min intervals. Fructose was determined at 20 -min intervals. 
Table 3. Protective effect of various substances (diluted in Krebs-Ringer solution) on the motility of washed ram spermatozoa ( $1 \mathrm{ml}$ suspension, $0.85 \times 10^{9} \mathrm{cells} / \mathrm{ml}$ ) treated with peroxidized arachidonic acid (final conc. in emulsion $=3 \mathrm{mg} / \mathrm{ml}$, peroxide value $=112 \mathrm{nmol} / \mathrm{mg}$ )

\begin{tabular}{lclc}
\hline \multicolumn{1}{c}{ First additive $(1 \mathrm{ml})$} & $\begin{array}{c}\text { Index of } \\
\text { initial } \\
\text { motility }\end{array}$ & Second additive $(\mathbf{1 ~ m l})$ & $\begin{array}{c}\text { Index of } \\
\text { motility after } \\
5 \text { min at } 22^{\circ} \mathrm{C}\end{array}$ \\
\hline Krebs-Ringer & 3 & Emulsion of arachidonic acid & 0 \\
Emulsion of arachidonic acid & 0 & Ringer & 0 \\
Dialysed egg yolk & 3 & Emulsion of arachidonic acid & 3 \\
Emulsion of arachidonic acid & 0 & Dialysed egg yolk & 0 \\
$10 \mathrm{mg}$ Brain fraction III & 3 & Emulsion of arachidonic acid & 1 \\
$10 \mathrm{mg}$ Brain fraction V & 3 & Emulsion of arachidonic acid & 1 \\
$10 \mathrm{mg}$ Egg-yolk lecithin & 3 & Emulsion of arachidonic acid & 1 \\
Milk & 3 & Emulsion of arachidonic acid & 1 \\
$5 \%$ Albumin & 3 & Emulsion of arachidonic acid & 0 \\
1 mM-Mercaptoethanol & 2 & Emulsion of arachidonic acid & 0 \\
$50 \mathrm{mg}$ Tocopherol & 3 & Emulsion of arachidonic acid & 0 \\
Dialysed bull seminal plasma & 1 & Emulsion of arachidonic acid & 0 \\
\hline
\end{tabular}

peroxide value $112 \mathrm{nmol} / \mathrm{mg}$ ), oxygen uptake was markedly reduced and fructolysis was abolished. On the other hand, a saturated fatty acid ( $2 \mathrm{mg}$ palmitic acid $/ 10^{9}$ cells) had no demonstrable effect. The uptake of oxygen by arachidonic acid incubated by itself, that is without spermatozoa, was higher than in a mixture with spermatozoa and fructose.

\section{Protective effects of phospholipids, anti-oxidants and certain semen diluents}

We have shown previously that in the presence of anti-oxidants or chelating agents the rate of peroxidation of endogenous phospholipids in spermatozoa was much lower (Jones \& Mann, 1976). We therefore investigated whether these agents would also prevent or reverse the toxic effects of exogenous peroxides. We also tested the influence of such commonly used semen diluents as egg yolk and milk.

The addition of $1 \mathrm{ml}$ of an emulsion of peroxidized arachidonic acid $(3 \mathrm{mg} / \mathrm{ml}$; peroxide value $112 \mathrm{nmol} / \mathrm{mg}$ ) to $1 \mathrm{ml}$ of a suspension of freshly washed ram spermatozoa, diluted with $1 \mathrm{ml} \mathrm{Krebs-}$ Ringer solution, was just sufficient to cause immediate immobilization (Table 3). The inhibition of motility could be prevented, but not reversed, by the addition of dialysed egg yolk, and to a lesser extent by milk, egg-yolk lecithin, and brain fractions III and V. Albumin, mercaptoethanol, tocopherol and dialysed bull seminal plasma all failed to exert any protective effect. In fact, the addition of dialysed bull seminal plasma by itself resulted in a reduction of sperm motility.

As shown in Text-fig. 1, the rates of fructolysis and oxygen uptake of spermatozoa that had been treated with egg yolk and peroxide were at first not greatly different from those of normal spermatozoa, but the protective effect of egg yolk subsequently waned and after $30-40 \mathrm{~min}$ incubation at $37^{\circ} \mathrm{C}$ all metabolic activity had ceased. All attempts to restore motility and metabolism by washing the inactivated spermatozoa with dialysed egg yolk failed and the addition of fructose, lactate or ATP also had no restorative effect. It appears, therefore, that the inhibition of the motility and metabolism of spermatozoa by exogenous fatty acid peroxides is to some extent preventable by the addition of protective agents such as dialysed egg yolk, but it cannot be reversed after the activity of spermatozoa has been abolished.

\section{Discussion}

In view of our earlier findings that the endogenous phospholipids of spermatozoa are susceptible to peroxidation, and that a peroxidation of this type is associated with an irreversible loss of motility, it was of interest to establish in the present study that exogenous fatty acid peroxides behave in a similar manner, i.e. cause immobilization of spermatozoa. If, therefore, the endogenous phospholipids of damaged or effete spermatozoa in an ejaculate undergo peroxidation, then the peroxides produced may become toxic to normal spermatozoa. This hypothesis is supported by several additional obser- 
vations. First of all, the rate at which peroxidation of endogenous phospholipids proceeds in spermatozoa which had sustained previous damage from physical or chemical factors is much higher than in intact spermatozoa (Jones \& Mann, 1977). Secondly, the part of the sperm cell that is particularly sensitive to endogenous or exogenous peroxidation damage is the acrosomal region. Lastly, once lipid peroxides are formed they are difficult to eliminate, and so their toxicity towards spermatozoa is bound to persist.

The type of action of exogenous fatty acid peroxides on spermatozoa is reminiscent of the spermicidal properties characteristic of a wide range of surface-active detergents and sulphydryl-binding agents (Mann, 1964). When fatty acid peroxides are added to spermatozoa they cause, like the detergents, extensive damage to the plasma membrane and are taken up or adsorbed by the spermatozoa. On the other hand, lipid peroxides also share certain properties with sulphydryl-reactive agents, such as $\mathrm{Cu}^{++}$or iodoacetate; the latter is well known to be spermicidal on account of its ability to block SH groups in certain intermediary enzymes of glycolysis. Since lipid peroxides damage SH-containing proteins and enzymes (Lewis \& Wills, 1962), it is tempting to speculate that this may be a way in which they inactivate spermatozoa. In this connection, two additional points may be raised. Firstly, spermatozoa possess an unusually high content of cysteine-rich structural proteins, and it has been shown that oxidation of SH groups and subsequent formation of S-S bonds is part of the normal maturation process of spermatozoa in the epididymis (Calvin \& Bedford, 1971). It is however conceivable that, if this type of oxidation is carried to excess, it may affect adversely the SH-dependent intermediary enzymes and thereby the motility of spermatozoa. Secondly, epididymal plasma from the cauda epididymidis of ram, boar and rabbit contains an exceptionally high concentration of hypotaurine ( $R$. Jones, unpublished observations), the anti-oxidant properties of which could be linked to its ability to protect protein-bound SH groups in spermatozoa, especially during prolonged storage in the epididymis. Experiments along these lines are now in progress.

The demonstration that egg yolk and milk protect spermatozoa from the deleterious effects of fatty acid peroxides is especially interesting since both materials are commonly included in semen diluents. It is difficult to say whether the egg yolk forms a protective coating on the sperm cell, hence preventing the fatty acid peroxide from interacting with the cell membrane, or whether it combines directly with the peroxide, thereby 'neutralizing' its toxic effects. A suspension of homogenized spermatozoa can also 'protect' motile spermatozoa from a toxic level of peroxidized fatty acid, presumably by taking up some of the peroxide and thereby reducing the amount available to the intact spermatozoa.

The seminal plasma is another potential source of organic peroxides in semen. The level of lipid phosphorus in ram seminal plasma $(3 \mathrm{mg} / 100 \mathrm{ml})$ is much less than that in spermatozoa (Mann, 1964). However, unsaturated plasmalogens, which form the natural substrate for peroxidation in spermatozoa (Jones \& Mann, 1976), constitute as much as 30-40\% of the total seminal plasma phospholipid (Quinn \& White, 1967). It is conceivable that under certain conditions this plasmalogen could become peroxidized. If this were so, then it might help to explain why seminal plasma has frequently been reported to have toxic effects on spermatozoa (Shannon, 1965; Dott, 1974).

\section{T.M. gratefully acknowledges support from the Leverhulme Trust Fund.}

\section{References}

Bernheim, F., Wilbur, K.M. \& Kenaston, C.B. (1952) The effect of oxidized fatty acids on the activity of certain oxidative enzymes. Archs Biochem. Biophys. $38,177-184$.

Calvin, H.I. \& Bedford, J.M. (1971) Formation of disulphide bonds in the nucleus and accessory structures of mammalian spermatozoa during epididymal maturation. J. Reprod. Fert., Suppl. 13, 65-75.

CORTESI, R. \& Privetr, O.S. (1972) Toxicity of fatty ozonides and peroxides. Lipids 7, 715-721.
Dickey, F.H., Cleland, G.H. \& Lotz, C. (1949) The rôle of organic peroxides in the induction of mutations. Proc. natn Acad. Sci, U.S.A. 35, 581-586.

DoTT, H.M. (1974) The effects of bovine seminal plasma on the impedance change frequency and glycolysis of bovine epididymal spermatozoa. J. Reprod. Fert. 38, 147-156.

Dubouloz, P. \& Fondarai, J. (1953) Sur le métabolisme des peroxydes lipidiques. II. Action des peroxydes lipidiques sur les groupements thiols protéiques. Bull. Soc. chim. Biol. 35, 819-826.

Downloaded from Bioscientifica.com at 04/26/2023 08:20:05AM via free access 
Ferreira, S.H. (1972) Prostaglandins, aspirin-like drugs and analgesia. Nature, New Biol. 240, 200-203.

Findlay, G.M., DRAPER, H.H. \& BergaN, J.G. (1970) Metabolism of $1 .{ }^{14} \mathrm{C}$-methyl linoleate hydroperoxide in the rabbit. Lipids 5, 970-975.

Horgan, V.J., Philpot, J. St. L., Porter, B.W. \& RoODYN, D.B. (1957) Toxicity of autoxidized squalene and linoleic acid, and of simpler peroxides, in relation to toxicity of radiation. Biochem. $J .67$, 551-558.

JoNes, R. \& MANN, T. (1973) Lipid peroxidation in spermatozoa. Proc. $R$. Soc. B 184, 103-107.

JONES, R. \& MANN, T. (1976) Lipid peroxidation in spermatozoa; formation, role of plasmalogen, and physiological significance. Proc. R. Soc. B 193, $317-$ 333.

JoNES, R. \& MANN, T. (1977) Damage to spermatozoa by peroxidation of endogenous phospholipids. $J$. Reprod. Fert. 50, 261-268.

LEWIS, S.E. \& Wills, E.D. (1962) The destruction of -SH groups of proteins and amino acids by peroxides of unsaturated fatty acids. Biochem. Pharmac. 11, 901-912.

Loveless, A. (1951) Qualitative aspects of the chemistry and biology of radiomimetic (mutagenic) substances. Nature, Lond. 161, 338-342.

MANN, T. (1964) The Biochemistry of Semen and of the Male Reproductive Tract. Methuen, London.

Mickel, H.S. \& HoRbar, J. (1974) The effect of peroxidized arachidonic acid upon human platelet aggregation. Lipids 9, 68-71.

Nishida, T., Tsuchiyama, H., INoue, M. \& Kummerow, F.A. (1960) Effect of intravenous injection of oxidized methyl esters of unsaturated fatty acids on chick encephalomalacia. Proc. Soc. exp. Biol. Med. 105, 308-312.
Olcotr, H.S. \& Dolev, A. (1963) Toxicity of fatty acid ester hydroperoxides. Proc. Soc. exp. Biol. Med. 114, 820-822.

QUINN, P.J. \& WHITE, I.G. (1967) Phospholipid and cholesterol content of epididymal and ejaculated ram spermatozoa and seminal plasma in relation to cold shock. Aust. J. biol. Sci. 20, 1205-1215.

Ross, W.C.J. (1950) Biological action of X-rays, nitrogen mustards, diepoxides and peroxides. Nature, Lond. 165, 808-809.

Roubal, W.T. \& TAPPEL, A.L. (1966) Damage to proteins, enzymes, and amino acids by peroxidizing lipids. Archs Biochem. Biophys. 113, 5-8.

ShannoN, P. (1965) Presence of a heat-labile toxic protein in bovine seminal plasma. $J$. Dairy Sci. 48, 1362-1365.

Swoboda, P.A.T. \& LeA, C.H. (1958) Determination of the peroxide value of edible fats by colorimetric iodometric procedures. Chemy Ind. 33, 1090-1091.

TSEN, C.C. \& COLLIER, H.B. (1960) The protective action of tocopherol against hemolysis of rat erythrocytes by dialuric acid. Canad.J. Biochem. Physiol. 38, 957964.

WILLs, E.D. (1961) Effect of unsaturated fatty acids and their peroxides on enzymes. Biochem. Pharmac. 7, 7-16.

WILLS, E.D. (1971) Effects of lipid peroxidation on membrane-bound enzymes of the endoplasmic reticulum. Biochem. J. 123, 983-991.

Wyss, O,, Stone, W.S. \& Clark, J.B. (1947) The production of mutations in staphylococcus aureus by chemical treatment of the substrate. J. Bact. 45, 767772.

Received 22 October 1976 